\title{
Variation of the intertrial interval in human classical conditioning
}

\author{
M. C. CARRILLO and L. T. THOMPSON \\ Northwestern University Medical School, Chicago, Illinois \\ J. D. E. GABRIELI \\ Stanford University, Stanford, Califormia \\ and \\ J. F. DISTERHOFT \\ Northwestern University Medical School, Chicago, Illinois
}

\begin{abstract}
The effect of using a short intertrial interval (ITI) in eyeblink classical conditioning in humans was examined. The performance of normal young adults in 750-msec delay conditioning was compared at ITIs of 5,10 , and $30 \mathrm{sec}$. All groups successfully acquired the task. Performance of each ITI group was similar for pseudoconditioning, conditioning, and extinction trials. Use of shorter ITIs during eyeblink conditioning should reduce test time and possible subject boredom or inattention, thus making the eyeblink conditioning task more useful as part of a neuropsychological test battery for evaluating brain damage and drug effectiveness. Shorter ITIs would also allow eyeblink classical conditioning to be used in concert with other technologies, such as PET scanning, to assess functional activity of the brain during learning.
\end{abstract}

The eyeblink conditioning paradigm has been widely used as a model system to study associative learning (Disterhoft, Kwan, \& Lo, 1977; R. F. Thompson et al., 1976). The neurobiological substrates underlying learning in this task have been extensively studied in animals (Disterhoft, L. T. Thompson, \& Moyer, 1994; Moyer, Deyo, \& Disterhoft, 1990; R. F. Thompson, 1991) and humans (Daum, Channon, Polkey, \& Gray 1991; Daum et al., 1993; Gabrieli et al., 1995; McGlinchey-Berroth et al., 1995; Weiskrantz \& Warrington, 1979). Parallels between animal and human data increase the usefulness of the model for studies of learning, memory, and aging (Gormezano, 1966; Solomon, Flint Beal, \& Pendlebury, 1988; WoodruffPak, 1988; Woodruff-Pak, Finkbiner, \& Katz, 1989). These parallels include similar acquisition rates, similar impairments in rate and level of acquisition in aging, the ability to use similar instrumentation and data reduction techniques to study learning in a variety of species (L. T. Thompson, Moyer, Akase, \& Disterhoft, 1994), and, apparently, similar neural circuitry showing enhanced blood flow during the associative learning task across species (Blaxton et al., 1996; Logan \& Grafton, 1995; Molchan,

This research was supported by NIH Grants F31 GM 17223 to M.C.C., AG08796 to J.F.D., and RR-00048 to the Clinical Research Center at Northwestern Memorial Hospital. Correspondence should be addressed to M. C. Carrillo, Department of Neurological Sciences, Section of Cognitive Neuroscience, Rush-Presbyterian-St. Luke's Medical Center, 1645 W. Jackson Blvd,, Suite 450, Chicago, IL 60612 (e-mail: mcarrill@rush.edu).

-Accepted by previous editor, Paul E. Gold
Sunderland, McIntosh, Herscovitch, \& Schreurs, 1994). The conceptual simplicity of the paradigm and the ease with which parameters can be adjusted are other advantages of eyeblink conditioning as a model of associative learning.

Classical conditioning involves the pairing of a neutral stimulus, such as a tone or conditioned stimulus, with a stimulus eliciting a reflexive response or unconditioned stimulus, such as the eyeblink reflex. The parameters of stimulus delivery usually remain constant throughout a test session. Parameters in classical conditioning include two time intervals. That most studied is the interstimulus interval (ISI), the time between onset of the conditioned stimulus (CS) and onset of the unconditioned stimulus (US). Optimal intervals for both animals (Gormezano \& Moore, 1969; Hoehler \& R. F. Thompson, 1980; Steinmetz, 1990) and humans (Solomon, Blanchard, Levine, Velazquez, \& Groccia-Ellison, 1991) have been demonstrated in past studies.

A second interval is the intertrial interval (ITI) (Figure 1A). The ITI in human eyeblink conditioning studies has been broadly studied, and results have been highly variable. Performance was found to increase with longer ITIs in a study using a light-airpuff (CS-US) pairing that tested 9-, 15-, 30-, 45-, 90-, and 135-sec ITIs (Prokasy, Grant, \& Myers, 1958; Spence \& Norris, 1950). A later study also using a light-airpuff pairing examined fixed and variable shorter ITIs and reported successful acquisition of a 450-msec delay eyeblink conditioning task with both a 4- and an 8-sec ITI and no difference in learning rate between a fixed and a varied interval (Prokasy, 1965). In a review of classical conditioning, Gormezano (1966) 
A.

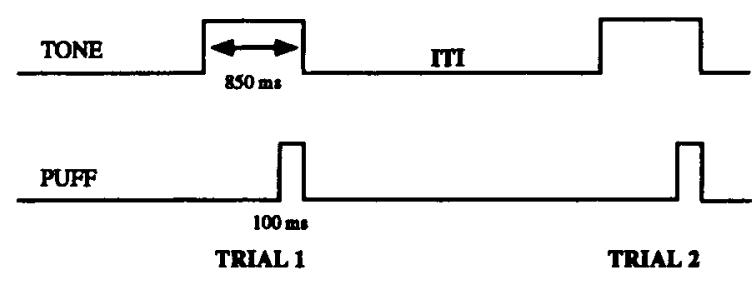

B.

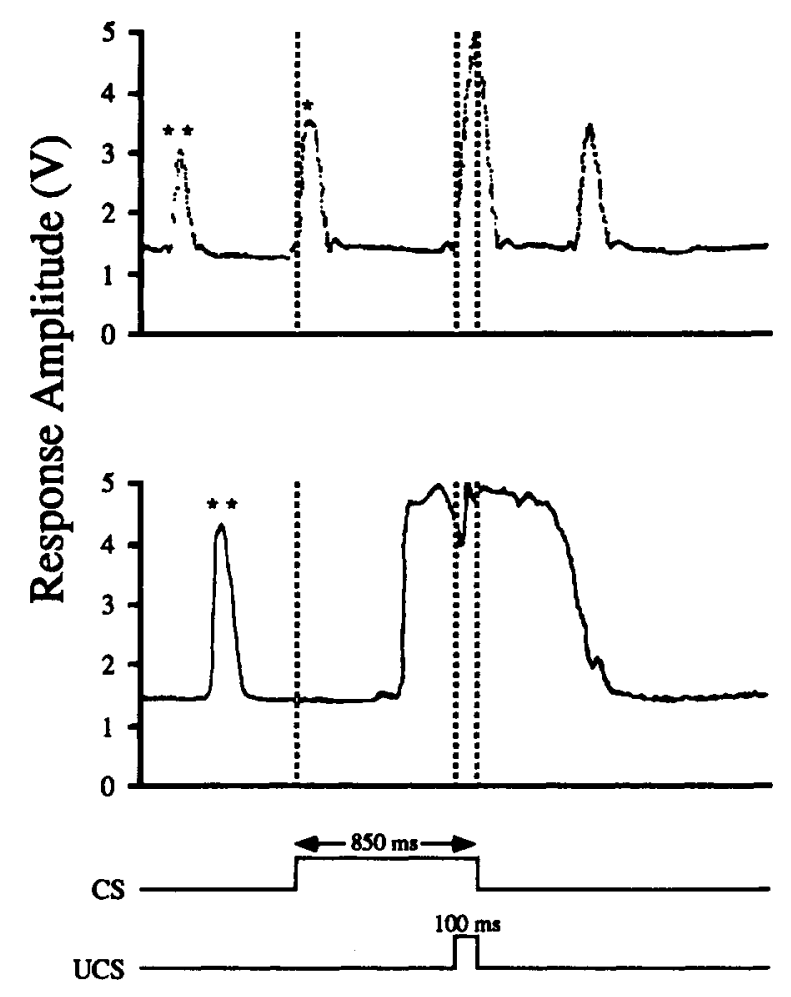

Figure 1. (A) Schematic of the intertrial interval and stimulus presentation timing parameters. (B) Examples of spontaneous blinks $\left({ }^{* *}\right)$ and alpha blinks $\left(^{*}\right)$ predominant in the shorter intertrial intervals.

described commonly used eyeblink classical conditioning parameters for humans that included a 15- to 25-sec ITI.

Currently, a variety of ITIs are being employed in human eyeblink conditioning studies. We wished to examine the ITI most commonly used, as well as shorter intervals (5 and $10 \mathrm{sec}$ ). An interval less than $30 \mathrm{sec}$ in duration would shorten test time for volunteers and reduce boredom or inattention during training. This would facilitate the use of eyeblink conditioning as a component of a neuropsychological test battery to evaluate the effects of drugs on brain damage and learning. The specific goal of the present study was to compare behavioral response characteristics between groups of normal young adult humans receiving eyeblink conditioning trials with ITIs that averaged 5,10 , and $30 \mathrm{sec}$ during pseudocondition- ing, acquisition, and extinction of this associative learning task.

\section{METHOD}

\section{Participants}

The participants in this study were 30 men and women, 20-35 years of age $(M$ age $=25.03$ years, $S D=3.52)$. The participants were recruited through advertisements posted at Northwestern University Medical School and received a small payment for their participation. The participants were randomly assigned to each of the three interval groups and received training with trials occurring at ITIs averaging 5,10 , or $30 \mathrm{sec}$.

\section{Apparatus}

The apparatus used was a modified version of that previously used in our laboratory for rabbit eyeblink conditioning (Akase, L. T. Thomp- 
son, \& Disterhoft, 1994; L. T. Thompson, Moskal \& Disterhoft, 1992; L. T. Thompson et al., 1994) and human eyeblink conditioning (Gabrieli et al., 1995; McGlinchey-Berroth et al., 1995). Eyeblink responses were measured with an infrared diode/photo transistor aimed at the eye. The detector was attached to an adjustable headband along with an airpuff delivery nozzle that was aimed at the right eye. Stimuli were delivered and responses were analyzed by an IBM-AT-compatible microcomputer.

\section{Procedure}

The participants were told they would be participating in an eyeblink experiment and were asked to sign an informed consent statement. They were seated and given a Folstein Mini-Mental Examination (MME) and were not included if they scored below the normal range of $28-30$ (Folstein, Folstein, \& McHugh, 1975). The participants were then fitted with the eyeblink apparatus and asked to make themselves comfortable while they watched a silent movie (Charlie Chaplin's Goldrush). Watching a silent movie during conditioning has been reported to improve alertness and alleviate boredom, while not interfering with acquisition (WoodruffPak \& R. F. Thompson, 1988). The experimenter was seated in the same room, out of the participant's view, and read the following instructions:

Please make yourself comfortable and watch the silent movie. Periodically, you will be experiencing different stimuli including some tones through the headphones and a mild puff of air in your right eye. Please feel free to blink whenever you want and let your natural reflexes take over and concentrate on the movie you are watching.

Parameters for conditioning were set as follows. The CS was an $85-\mathrm{dB}, 1-\mathrm{kHz}$ tone, $850 \mathrm{msec}$ in duration with a $5-\mathrm{msec}$ rise/fall time, delivered binaurally with earphones, followed by a 100 -msec 3 -psi corneal airpuff US. Trials occurred with an ISI of $750 \mathrm{msec}$ and an ITI of 5,10 , or $30 \mathrm{sec}$ (Figure 1A). The computer monitored eyeblinks for a baseline period of $750 \mathrm{msec}$ prior to the onset of the CS. In total, eyeblinks were monitored for $3,000 \mathrm{msec}$ per trial.

Eyeblink conditioning sessions consisted of 30 pseudoconditioning, 60 conditioning, and 30 extinction trials. Pseudoconditioning trials consisted of randomized, explicitly unpaired CS and US presentations given in the same total elapsed time as would have occurred during 15 conditioning trials. These trials were used to determine unconditioned response (UR) amplitudes and basal rates for eyeblinks to CS-alone presentations. Responses to CS-alone presentations that met conditioned response (CR) criteria were quantified and compared across intervals, serving as a control for spontaneous blink activity. Conditioning trials consisted of 12 blocks of 5 paired CS and US presentations. Extinction trials consisted of 4 blocks of 5 tone CS-alone presentations. After the session was completed, the participants were briefly interviewed on the purpose of the experiment.

\section{Data Analysis}

A CR was defined as an eyeblink 4 standard deviations greater than the mean baseline response amplitude, occurring after CS onset and before US onset. Spontaneous blink rate was monitored in the baseline period prior to the onset of the CS and quantified to assess group differences. Blinks occurring during the first $100 \mathrm{msec}$ of the CS were considered alpha or short-latency responses and not CRs (Gormezano, 1966).

Mean number of CRs was analyzed by blocks of 5 trials with one-way repeated measures analyses of variance (ANOVAs) to examine interval differences for pseudoconditioning, conditioning, and extinction trials. The mean number, latency, and amplitude of CRs and the mean amplitude of URs were calculated for each subject. A one-way ANOVA examined interval differences for these measures.

\section{RESULTS}

\section{Mini-Mental State Examination}

All subjects scored within the normal range of 28-30 $(M=29.73, S D=0.521)$.

\section{Acquisition of Conditioned Responses}

Pseudoconditioning trials were randomly presented and analyzed in three blocks of 5 trials (Figure 2A). A repeated measures ANOVA indicated no significant difference in overall responses to the tone $\operatorname{CS}[F(2,27)=0.513$, n.s.] (Figure 2B, Table 1) or response rate $[F(2,54)=$ 0.416 , n.s.], and no significance for the conditioning $X$ ITI interaction $[F(4,54)=1.021]$.

Conditioning trials of CS-US pairing were analyzed in 12 blocks of 5 trials (Figure 2A). A repeated measures ANOVA indicated no significant difference in overall conditioning performance $[F(2,27)=0.353$, n.s.] (Figure 2B, Table 1). A significant difference was observed in rate of conditioning across blocks (i.e., acquisition occurred) $[F(11,297)=2.519, p<.001]$, and the conditioning $\times$ ITI interaction was not significant $[F(22,297)=$ $0.851, p<.05]$.

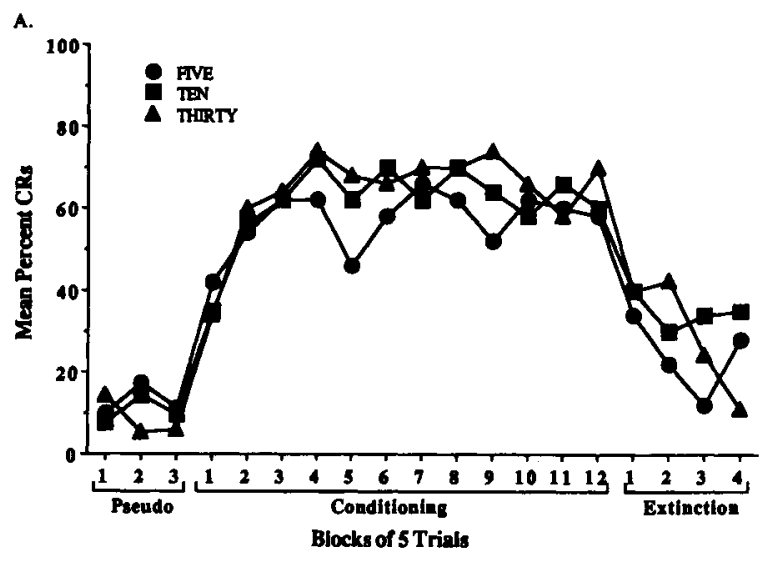

B.

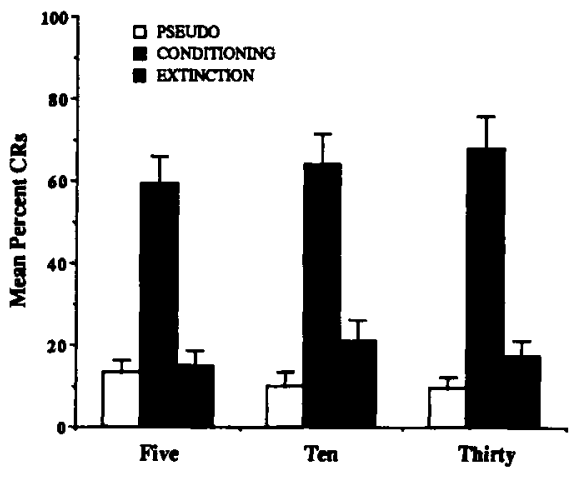

Figure 2 (A) Mean percent conditioned responses for subjects in each intertrial interval across pseudoconditioning, conditioning, and extinction blocks. (B) Mean percent conditioned responses for overall performance in each intertrial interval. 
Table 1 Mean Percent Conditioned Responses

\begin{tabular}{|c|c|c|c|c|c|c|c|}
\hline \multirow[b]{2}{*}{ ITI } & \multirow[b]{2}{*}{$n$} & \multicolumn{2}{|c|}{ Pseudo } & \multicolumn{2}{|c|}{ Conditioning } & \multicolumn{2}{|c|}{ Extinction } \\
\hline & & $M$ & $S D$ & $M$ & $S D$ & $M$ & $S D$ \\
\hline $5 \mathrm{sec}$ & 10 & 13.3 & 15.1 & 57.0 & 19.8 & 24.0 & 17.4 \\
\hline $10 \mathrm{sec}$ & 10 & 10.0 & 17.5 & 63.5 & 23.1 & 34.8 & 22.0 \\
\hline $30 \mathrm{sec}$ & 10 & 9.7 & 12.9 & 65.5 & 21.9 & 29.4 & 19.3 \\
\hline
\end{tabular}

Extinction trials, CS-alone presentations immediately after conditioning, were analyzed in 4 blocks of 5 trials (Figure 2A). Responses showed a decrease in CRs that reached the baseline previously established during pseudoconditioning. A repeated measures ANOVA indicated no difference in mean percent $C$ Rs for extinction $[F(2,26)=$ 0.725 , n.s.] (Figure 2B, Table 1). A significant difference in extinction rate across blocks was observed, indicating a significant decrease in CR across conditioning blocks $[F(2,3)=3.417, p<.05]$, but the extinction $\times$ ITI interaction was not significant, indicating no difference in rate of extinction between the ITI groups $[F(2,6)=$ 0.966, n.s.].

\section{Response Characteristics}

CR amplitudes and CR latencies were compared for conditioning trials. Analysis revealed no significant differences among the ITI groups for amplitudes and latencies across conditioning blocks (Table 2).

Unconditioned response amplitudes were compared for pseudoconditioning, conditioning, and extinction trials. Analysis indicated no significant difference among the ITI groups across all blocks (Table 2).

\section{Spontaneous Blink and Alpha Response Rate}

Spontaneous blinks and alpha responses as described above were quantified during pseudoconditioning, conditioning, and extinction. Analysis revealed no difference between groups for spontaneous blinks or alpha response activity during pseudoconditioning, conditioning, or extinction. Although not statistically significant, a trend in the data indicated that there was an increase in spontaneous blinks and alpha responses when the ITI was decreased to $5 \mathrm{sec}$.

\section{DISCUSSION}

The most important finding of the present study was that human eyeblink conditioning rates appeared not to be detrimentally affected by trials presented at very short intervals, at least when acquisition occurred within one session. No difference in learning rate or in asymptotic eyeblink conditioning levels was observed between groups trained in eyeblink conditioning with a tone CS and airpuff US and using a 5-, 10-, or 30-sec average ITI. These findings are contrary to previous reports that longer ITIs enhanced eyeblink conditioning rates in humans (Prokasy et al., 1958; Spence \& Norris, 1950), but they are consistent with a report by Prokasy (1965) in which two shorter ITIs of 4 and $8 \mathrm{sec}$ resulted in successful acqui- sition of a 450-msec light-airpuff delay eyeblink conditioning task.

The shorter ITI groups (especially the 5-sec ITI group) were expected to demonstrate a considerable amount of sensitization, which would be manifest by increasing numbers of spontaneous blinks in the baseline period or increasing numbers of nonassociative alpha responses to tone presentation. We therefore examined our data quite carefully for evidence of nonspecific responding in any of the conditioning groups. However, the same number of alpha responses and spontaneous blinks occurred in each of the ITI groups. A slight trend toward an increased number of nonspecific responses was observed in the 5and 10 -sec ITI groups, although this trend was not statistically significant.

Another type of nonassociative response that can contaminate human eyeblink conditioning data is the voluntary response. It has been described as a sharp, complete closure maintained until after termination of the airpuff US (Spence \& Taylor, 1951). The difference between a conditioned participant and a voluntary responder has not been agreed upon in the literature (Coleman \& Webster, 1988). Spence and Ross (1959) devised a latency criterion used to exclude voluntary responders from data sets, and they suggest that the two types of responders are governed by different laws. However, the method was not widely used. Gormezano and Moore (1962) offer an alternative interpretation of voluntary responders as "highly conditionable subjects." They also indicate that, with a set of neutral instructions, an experimenter can request that the participant neither aid nor inhibit his/her eyelid responses. Our data analysis techniques were patterned after Gormezano's (1966) human eyeblink conditioning model. A neutral instruction set and viewing a silent movie are methods we have employed to reduce the participant's ability to consciously control eyeblink responses to the tone $\mathrm{CS}$, thus ensuring reliable conditioning results.

Various studies in humans have used an average ITI of 30-60 sec (Solomon et al., 1988; Solomon \& Morse, 1989; Solomon, Pomerleau, Bennett, James, \& Morse, 1989; Solomon, Stowe, \& Pendlebury, 1990; Woodruff-Pak \& R. F. Thompson, 1988). Others have used ITIs as short as 4 and 8 sec (Little, Lippsitt, \& Rovee-Collier, 1984; Prokasy, 1965) and 10-12 sec (Channon, Daum, \& Gray, 1993; Gabrieli et al., 1995; McGlinchey-Berroth et al., 1995). An intermediate interval of $20 \mathrm{sec}$ has also been reported (Ferrante \& Woodruff-Pak, 1995). Given the practical consideration that the presentation of 50 conditioning trials at a 10 -sec ITI would require only $4 \mathrm{~min}$

Table 2

Mean Conditioned Response Amplitude and Latency

\begin{tabular}{|c|c|c|c|c|c|c|}
\hline \multirow[b]{2}{*}{ ITI } & \multicolumn{2}{|c|}{ CR Amp (mV) } & \multicolumn{2}{|c|}{$\mathrm{UR} \operatorname{Amp}(\mathrm{mV})$} & \multicolumn{2}{|c|}{ CR Lat (msec) } \\
\hline & $M$ & $S D$ & $M$ & $S D$ & $M$ & $S D$ \\
\hline $5 \mathrm{sec}$ & $1,511.5$ & 867.0 & $2,630.7$ & 553.1 & 463.9 & 63.3 \\
\hline $10 \mathrm{sec}$ & $1,463.1$ & 759.4 & $2,699.0$ & 684.2 & 456.3 & 62.6 \\
\hline $30 \mathrm{sec}$ & $1,411.1$ & 499.6 & $2,848.3$ & 520.7 & 498.1 & 66.5 \\
\hline
\end{tabular}

Note - CR, conditioned response; UR, unconditioned response. 
more than the same number of trials at a 5 -sec ITI, and that asymptotic conditioning levels were very solid in our subjects with 10 -sec ITI, the 10-sec ITI would appear to be optimal.

One of the motivating factors in carrying out this study was to attempt to improve the utility of eyeblink conditioning as a neuropsychological tool for analysis of the effects of aging, brain damage, or neuropharmacological agents on learning in the human. In our experience, participants have found the $30-\mathrm{sec}$ average ITI condition too long and have trouble maintaining their attention during training sessions. Their motivation to participate in return visits is also lower, such as in a drug trial that demands a baseline visit plus one or more return visits. In addition, if it were possible to eyeblink-condition participants in a relatively short time period, this task could be included as one of a focused battery of tests for drug or neuropsychological evaluations. Our data demonstrated clearly that asymptotic acquisition in the eyeblink conditioning task occurred well within 20 training trials, which would take less than $5 \mathrm{~min}$ to administer using a 10 -sec average interval.

A second motivating factor involves the recent development in and use of emerging neuroimaging techniques (specifically, PET scanning). Studies in which participants are trained within a PET scanner must optimize cognitive activity during the 2-min interval surrounding successive brain scans. The data summarized here would indicate that bursts of trials could be delivered during each scan at short 5- or 10-sec ITIs and still support reasonable levels of behavioral acquisition as we reported in a PET scanning study (Blaxton et al., 1996). This approach could reveal detectable alterations in regional blood flow that may be correlated with early and late acquisition of the eyeblink conditioning task.

\section{REFERENCES}

AKase, E., Thompson, L. T., \& Disterhoft, J. F. (1994). A system for quantitative analysis of associative learning: Part 2. Real-time software for MS-DOS microcomputers. Journal of Neuroscience Methods, 54, 119-127.

Blaxton, T. A., Zeffiro, T. A., Gabrieli, J. D. E., Bookheimer, S. Y., Carrillo, M. C., Theodore, W. H., \& Disterhoft, J. F. (1996). A functional mapping of human learning: A PET activation study of eyeblink conditioning. Journal of Neuroscience, 16, 4032-4040.

Channon, S., Daum, I., \& Gray, J. A. (1993). Operant conditioning after temporal lesions in man: Conditional and simple discrimination learning. Cortex, 29, 315-324.

Coleman, S. R., \& Webster, S. (1988). The problem of volition and the conditioned reflex: II. Voluntary-responding subjects, 1951-1980. Behaviorism, 16, 17-49.

Daum, I., Channon, S., Polkey, C. E., \& Gray, J. A. (1991). Classical conditioning after temporal lobe lesions in man: Impairment in conditional discrimination. Behavioral Neuroscience, 105, 396-408.

Daum, I., Schugens, M. M., Ackermann, H., Lutzenberger, W., Dichgans, J., \& Birbaumer, N. (1993). Classical conditioning after cerebellar lesions in humans. Behavioral Neuroscience, 107, 748-756.

Disterhoft, J. F., KwaN, H. H., \& Lo, W. D. (1977). Nictitating membrane conditioning to tone in the immobilized albino rabbit. Brain Research, 137, 127-143.

Disterhoft, J. F., Thompson, L. T. \& Moyer, J. R., Jr. (1994). Cellu- lar mechanisms of associative learning in the hippocampus. In J. Delacour (Ed.), Neural mechanisms of learning and memory (pp. 431-492). Singapore: World Scientific.

FERrante, L. S., \& WoOdrufF-PaK, D. S. (1995). Longitudinal investigation of eyeblink classical conditioning in elderly human subjects Journal of Gerontology: Psychological Sciences, 50B, P42-P50.

Folstein, M. F., Folstein, S. E., \& MCHugh, P. R. (1975). "Minimental state": A practical method for grading cognitive state of patients for the clinician. Journal of Psychiatric Research, 12, 189-198.

Gabrieli, J. D. E, McGlinchey-Berroth, R., Carrillo, M. C., Gluck, M. A., CermaK, L. S., \& Disterhoft, J. F. (1995). Intact delay-eyeblink conditioning in amnesia. Behavioral Neuroscience, 109, 819-827.

GoRmezano, I. (1966). Classical conditioning. In J. B. Sidowski (Ed.), Experimental methods and instrumentation in psychology (pp. 385420). New York: McGraw-Hill.

GORMEZANO, I., \& MOORE, J. W. (1962). Effects of instructional set and UCS intensity on the latency, percentage, and form of the eyelid response. Journal of Experimental Psychology, 63, 487-494.

Gormezano, I., \& MOORE, J. W. (1969). Classical conditioning, In M. H. Marx (Ed.), Learning processes (pp. 385-420). New York: Macmillan.

HoEHLER, F. K., \& THOMPSON, R. F. (1980). Effect of the interstimulus (CS-US) interval on hippocampal unit activity during classical conditioning of the nictitating membrane response of the rabbit (Oryctolagus cuniculus). Journal of Comparative \& Physiological Psychology, 94, 201-215.

LitTle, A. H., LippsitT, L. P., \& Rovee-Collier, C. (1984). Classical conditioning and retention of the infant's eyelid response: Effects of age and interstimulus interval. Journal of Experimental Child Psychology, 37, 512-524.

LOGAN, C. G., \& GRAFTON, S. T. (1995). Functional anatomy of human eyeblink conditioning determined with regional cerebral glucose metabolism and positron-emission tomography. Proceedings of the $\mathrm{Na}$ tional Academy of Sciences, 92, 7500-7504.

McGlinchey-Berroth, R., Cermak, L. S., Carrillo, M. C., ArmFIELD, S., Gabrieli, J. D. E., \& Disterhoft, J. F. (1995). Impaired eyeblink conditioning in amnesic Korsakoff's patients and recovered alcoholics. Alcoholism: Clinical \& Experimental Research, 19, 1127 1132.

Molchan, S. E., Sunderland, T., McIntosh, A. R., Herscovitch, P., \& SChreurs, B. G. (1994). A functional anatomical study of associative learning in humans. Proceedings of the National Academy of Sciences, 91, 8122-8126.

MOYER, J. R., Deyo, R. A., \& Disterhoft, J. F. (1990). Hippocampectomy disrupts trace eye-blink conditioning in rabbits. Behavioral Neuroscience, 104, 242-252.

ProKasY, W. F. (1965). Stimulus fluctuation, reactive inhibition, and time between trials in classical eyelid conditioning. Journal of Experimental Psychology, 70, 464-472.

Prokasy, W. F., Grant, D. A., \& Myers, N. A. (1958). Eyelid conditioning as a function of unconditioned stimulus intensity and intertrial interval. Journal of Experimental Psychology, 55, 242-246.

Solomon, P. R., Blanchard, S., Levine, E., Velazquez, E., \& Groccia-ElLISON, M. (1991). Attenuation of age-related conditioning deficits in humans by extension of the interstimulus interval. Psychology \& Aging, 6, 36-42.

Solomon, P. R., Flint Beal, M., \& Pendlebury, W. W. (1988). Agerelated disruption of classical conditioning: A model systems approach to memory disorders. Neurobiology of Aging, 9, 535-546.

SOlOMON, P. R., \& MORSE, D. L. (1989). Acquisition of the classically conditioned eyeblink response in humans over the life span. Psychology \& Aging, 4, 34-41.

Solomon, P. R., Pomerleau, D., Bennett, L., James, J., \& Morse, D. L. (1989). Acquisition of the classically conditioned eyeblink response in humans over the lifespan. Psychology \& Aging, 3, 34-41.

Solomon, P. R., Stowe, G. T., \& Pendlebury, W. W. (1990). Disrupted eyelid conditioning in a patient with damage to the cerebellar inputs. Behavioral Neuroscience, 103, 898-902.

SPENCE, K. W., \& NoRrIS, E. B. (1950). Eyelid conditioning as a function of the inter-trial interval. Journal of Experimental Psychology, 40, 716-720. 
SPENCE, K. W., \& Ross, L. E. (1959). A methodological study of the form and latency of eyelid responses in conditioning. Journal of Experimental Psychology, 58, 376-381.

SPENCE, K. W., \& TAYLOR, J. (1951). Anxiety and strength of the UCS as determiners of the amount of eyelid conditioning. Journal of Experimental Psychology, 42, 183-188.

Steinmetz, J. E. (1990). Classical nictitating membrane conditioning in rabbits with varying interstimulus intervals and direct activation of cerebellar mossy fibers as the CS. Behavioural Brain Research, 38, 97-108.

Thompson, L. T., Moskal, J. R., \& DisterhofT, J. F. (1992). Hippocampus-dependent learning facilitated by a monoclonal antibody or D-cycloserine. Nature, 359, 638-641.

Thompson, L. T., MOYer, J. R., AKase, E., \& Disterhoft, J. F. (1994). A system for quantitative analysis of associative learning: Part 1. Hardware interfaces with cross-species applications. Journal of Neuroscience Methods, 54, 109-117.

THOMPSON, R. F. (1991). Are memory traces localized or distributed? Neuropsychologia, 29, 571-582.
Thompson, R. F., Berger, T. W., Cegavske, C. F., Patterson, M. M., Roemer, R. A., Teyler, T. J., \& Young, R. A. (1976). A search for the engram. American Psychologist, 31, 209-227.

Weiskrantz, L., \& Warrington, E. K. (1979). Conditioning in amnesic patients. Neuropsychologia, 17, 187-194.

WoOdruff-Pak, D. S. (1988). Aging and classical conditioning: Parallel studies in rabbits and humans. Neurobiology of Aging, 9, 511-522.

Woodruff-Pak, D. S., Finkbiner, R. G., \& Katz, I. R. (1989). A model system demonstrating parallels in animal and human aging: Extension to Alzheimer's disease. In E. M. Meyer, J. W. Simpkins, \& J. Yamamoto (Eds.), Novel approaches to the treatment of Alzheimer's disease (pp. 355-371). New York: Plenum.

Woodruff-PaK, D. S., \& Thompson, R. F. (1988). Classical conditioning of the eyeblink response in the delay paradigm in adults aged 18-83 years. Psychology \& Aging, 3, 219-229.

(Manuscript received May 29, 1996;

revision accepted for publication November 29, 1996.) 